Çukurova Üniversitesi Mühendislik Mimarlık Fakültesi Dergisi, 34(4), ss. 193-201, Aralık 2019

Çukurova University Journal of the Faculty of Engineering and Architecture, 34(4), pp. 193-201, December 2019

\title{
Reaktör Türlerinin ve Parametrelerinin Steam Reforming Prosesiyle Etanolden Hidrojen Üretimine Etkisinin Aspen Plus ile İncelenmesi
}

\author{
Mesut BEKİROĞULLARI ${ }^{* 1}$, Mustafa KAYA ${ }^{1}$ \\ ${ }^{1}$ Siirt Üniversitesi, Mühendislik Fakültesi, Kimya Mühendisliği Bölümü, Siirt
}

Geliş tarihi: 26.03.2019 Kabul tarihi: 20.12.2019

\section{$\ddot{O} z$}

$\mathrm{Bu}$ çalışmada etanolden hidrojen üretim prosesi Aspen Plus yardımıyla geliştirilmiştir. Geliştirilen simülasyon kullanılarak öncelikle üç farklı reaktör türünün etanol dönüşüm oranlarına etkisi incelenmiş olup RGibss reaktörünün REquilibrium ve RPlug reaktörlerien oranla en iyi dönüşüm oranına sahip olduğu belirlenmiştir. İki farklı aktivite katsayısı modeli olan UNIFAC ve UNIQUAC modelleri test edilmiş olup en iyi dönüşüm oranının UNIQUAC modelinde olduğu tespit edilmiştir. En iyi reaktör ve aktivite katsayısı modeli belirlendikten sonra, sıcaklık, basınç ve karışım oranı gibi reaktör çalışma parametrelerinin etanol dönüşüm oranına olan etkileri sırasıyla çalışılmıştır. Yapılan çalışma neticesinde sıcaklık, basınç ve karışım oranı sırasıyla $500^{\circ} \mathrm{C}$, 1 atm ve $1 / 4$ olarak belirlenmiştir. Son olarak üretilen hidrojen gazının saflaştırılıp kullanabilir hale gelmesi için bir ayrıștırıcı kullanılmış olup \%99,9 saflıkta saf H2 elde edilmiştir. Elde edilen veriler Aspen Plus simülatörünün başarılı bir şekilde gerçekleştirildiğini göstermekte olup bu tür başarılı simülasyonların deneysel maliyetleri ve zaman kaybını minimize edebileceğini göstermektedir.

Anahtar Kelimeler: Aspen plus, Etanol, Hidrojen enerjisi, Steam reforming, Reactör şartları

\section{Effect of Reactor Types and Operating Parameters for the Hydrogen Production through Steam Reforming Process of Ethanol}

\begin{abstract}
In the present study, hydrogen production process from ethanol was developed with the aid of Aspen Plus. Firstly, the effect of reactor types on ethanol conversion rates was investigated by simulating three different reactors in Aspen Plus and it was determined that the RGibss reactor provided the best conversion rate compare to REquilibrium and RPlug. Two different activity coefficient models, UNIFAC and UNIQUAC, have been tested and the best conversion rate has attained with the use UNIQUAC model. Once the optimal best reactor type and activity coefficient model were decided, the effects of reactor operating parameters such as temperature, pressure and mixing ratio on ethanol conversion rate were studied respectively. Temperature, pressure and mixing ratio for the optimal conversion rate of ethanol were determined as $500{ }^{\circ} \mathrm{C}, 1 \mathrm{~atm}$ and $1 / 4$ respectively. Finally, a separator was used to purify the hydrogen gas and pure $\mathrm{H} 2$ with a purity of $99.9 \%$ was subsequently produced. The obtained data indicate that Aspen Plus simulator has been performed successfully and shows that such successful simulations can minimize experimental costs and time loss.
\end{abstract}

Keywords: Aspen plus, Ethanol, Hydrogen energy, Steam reforming, Reactor conditions

*Sorumlu yazar (Corresponding author): Mesut BEKİROGULLARİ, mesutbekirogullari@siirt.edu.tr 


\section{GİRIŞ}

Artan küreselleşme ve sanayileşmeye paralel olarak enerji ihtiyacı da hızla artmaktadır. Günümüzde enerji ihtiyacının büyük bir kısmı petrol ve kömür gibi fosil yakıtlar (yenilemeyen) ile karşılanmaktadır. Fosil yakıtların hızla tükenmeye başlaması ve üretiminin ve kullanımın sebep olmuş olduğu küresel ısınma sorunlarından dolayı yenilebilir ve sürdürülebilir çevre dostu enerji kaynaklarına olan ilgi gün geçtikçe artmaktadır. Güneş, rüzgâr, hidroelektrik, jeotermal, biyokütle ve hidrojen enerjisi yenilebilir enerji kaynaklarının başlıcalarındandır. Doğada en yaygın olarak bulunan element olan hidrojen doğada bileşikler halinde bulunmaktadır. Hidrojen genellikle suda, biyokütlede ve hidrokarbonların yapısında yer alır. Hidrojen enerjisi bu bileşiklerin fiziksel ve kimyasal işlemlerle işlenmesi sonucu elde edilen enerji kaynağıdır. Hidrojen enerjisi doğal bir enerji kaynağı olmamakla beraber, çevre dostu, sürdürülebilir ve yenilebilir enerji kaynakları arasında yer almaktadır. Tüm bu avantajlarının yanı sıra hidrojen enerjisi düşük emisyon değerine, verimlilik, düşük maliyet ve yüksek kalorifik enerji içeriği sayesinde geleceğin en önemli enerji kaynakları arasında yer almaktadır [1-3].

Hidrojen enerjisi doğal gaz, nafta, ağır yağlar, metanol, biyokütle, atıklar, kömür ve rüzgar enerjisi gibi birçok kaynaktan elde edilmektedir [3]. Hidrojen enerjisinde kimyasal enerji $\mathrm{H}-\mathrm{H}$ bağları içerisinde depolanır ve oksijen ile yakıldığı zaman yanma ürünü olarak yalnızca su açığa çıkar ve buda hidrojen enerjisinin temiz bir enerji kaynağı olarak kabul görmesini sağlamaktadır [3] Tüm bunlar göz önünde bulundurulduğunda enerji kaynakları ve çevre ile ilgili sorunlara çözüm bulmak amaciyla hidrojen enerjisine dayalı bir enerji altyapısının çözüm olabileceği düşünülmektedir. Önümüzde ki yıllarda sanayide (örneğin amonyak yapımı) ve enerji alanında (örneğin yakıt hücreleri) kullanılmak üzere hidrojene olan talebin hizla artması beklenmektedir. Bundan dolayı yakın gelecekte hidrojen enerjisi elde edilmesi için var olan bioyakıt kaynaklarının kullanılması öncelikli olacaktır [4].
Günümüzde hidrojen gazı elde etmek için steam reforming, autothermal reforming ve partial oxidation prosesleri gibi çeşitli yöntemler kullanılmaktadır [5]. Belirtilen bu üç yöntem arasında steam reforming prosesi düşük sıcaklıkta çalışabilmesi ve oksijen ihtiyacı olmaması gibi önemli avantajlarından dolayı endüstriyel düzeyde en çok gelişmiş ve en yaygın kullanılan yöntemdir [6]. Steam reforming prosesinde hidrokarbonlardan hidrojen gazı eldesine ait reaksiyon stokiyometrisi Eşitlik 1'deki gibidir [2];

$\mathrm{C}_{\mathrm{x}} \mathrm{H}_{\mathrm{y}}+\mathrm{xH}_{2} \mathrm{O} \rightarrow\left(\mathrm{x}+\frac{\mathrm{y}}{2}\right) \mathrm{H}_{2}+\mathrm{xCO}_{2}$

Fosil yakıtlar sebep oldukları çevresel sorunlar ve bilinen fosil yakıt yataklarının hızla tükenmeye başlamasıyla hidrojen enerjisi elde edilmesinde kullanılmasında çok fazla tercih edilmemektedirler. $\mathrm{Bu}$ kapsamda yenilenebilir enerji kaynaklarının hidrojen enerjisi elde edilmesinde kullanılması oldukça önem kazanmaktadır. Tüm bunlar dikkate alındığında fermantasyon prosesiyle oldukça yüksek miktarda üretilebilen etanol önemli bir kaynak haline gelmektedir (Eşitlik 2);

$\mathrm{C}_{12} \mathrm{H}_{22} \mathrm{O}_{11}+\mathrm{H}_{2} \mathrm{O} \rightarrow 4 \mathrm{CH}_{3} \mathrm{CH}_{2} \mathrm{OH}+4 \mathrm{CO}_{2}$

Sakkaroz $+\mathrm{Su} \rightarrow$ Etanol+Karbondioksit

Hidrojen enerjisi elde etmek için kullanılabilecek en önemli hammadde kaynağı olan etanolün steam reforming prosesindeki reaksiyon gerçekleşme aşamaları şu şekildedir (Eşitlik 3-8);

$$
\begin{aligned}
& \mathrm{C}_{2} \mathrm{H}_{5} \mathrm{OH}+3 \mathrm{H}_{2} \mathrm{O} \rightarrow 2 \mathrm{CO}_{2}+6 \mathrm{H}_{2} \\
& \mathrm{C}_{2} \mathrm{H}_{5} \mathrm{OH}+\mathrm{H}_{2} \mathrm{O} \rightarrow 2 \mathrm{CO}+4 \mathrm{H}_{2} \\
& \mathrm{C}_{2} \mathrm{H}_{5} \mathrm{OH}+2 \mathrm{H}_{2} \rightarrow 2 \mathrm{CH}_{4}+\mathrm{H}_{2} \mathrm{O} \\
& \mathrm{C}_{2} \mathrm{H}_{4}+2 \mathrm{H}_{2} \mathrm{O} \rightarrow 2 \mathrm{CO}+4 \mathrm{H}_{2} \\
& \mathrm{CH}_{4}+\mathrm{H}_{2} \mathrm{O} \rightarrow 3 \mathrm{H}_{2}+\mathrm{CO} \\
& \mathrm{CO}+\mathrm{H}_{2} \mathrm{O} \rightarrow \mathrm{CO}_{2}+\mathrm{H}_{2}
\end{aligned}
$$


Steam reforming prosesi ile etanolden hidrojen gazı elde edilmesine ait genel reaksiyon akışı yukarıda verilmiştir $[7,8]$. Gerçekleşmesi beklenen diğer yan reaksiyonların daha detaylı bir listesi Wu ve arkadaşları [3] ve Murmura, ve arkadaşları [9] tarafindan verilmiştir.

$\mathrm{Bu}$ çalışma kapsamında gelecekte sanayi çaplı üretimine geçilmesine beklenen steam reforming prosesiyle etanolden hidrojen üretimine reaktör türünün ve parametrelerinin hidrojen üretimine etkisinin Aspen Plus ile incelenmesi gerçekleştirilmiştir. Kullanılan simülasyon programı içerisinde barındırdığı veri bankası sayesinde deneysel çalışma gerçekleştirmeden önce üretime etki eden sıcaklık ve basınç gibi parametrelerin incelenmesine olanak sağlamaktadır. Ayrıca Aspen Plus simülatörü ekonomik analiz yapılmasına da imkan vermektedir. $\mathrm{Bu}$ çalışmada öncelikle steam reforming prosesinde kullanılması beklenen reaktör türleri etanol dönüşüm oranları göz önünde bulundurularak incelenmiştir. Daha sonrasında belirlenen reaktör kullanılarak proseste kullanılabilecek olan en verimli termodinamik model (UNIFAC, UNIQUAC) belirlenmiştir. Son olarak, reaktör sıcaklığı, basıncı ve karıșım oranı incelenerek en optimal sistem belirlenmiştir.

\section{MATERYAL VE METOT}

Aspen Plus simülatörü kullanılarak steam reforming prosesine ait proses akış şeması Şekil 1'de verildiği gibi oluşturulmuştur. Proses akış diyagramında da açıkça görüldüğü gibi proseste iki tane hammadde girişi (etanol ve su) vardır. Hammaddelerin giriş sıcaklık ve basınçları sırasıyla $25{ }^{\circ} \mathrm{C}$ ve $1 \mathrm{~atm}$ 'dir. Her iki hammaddenin başlangıç akış hızları sırasıyla $10 \mathrm{kmol} / \mathrm{s}$ ve $30 \mathrm{kmol} / \mathrm{s}$ olarak belirlenmiștir. Bu iki hammadde bir karıştırıcı (mixer) kullanılarak karıştırılıp reaktör sıcaklığgna getirilmek üzere bir ısıtıcıya (heater) gönderilmiștir. Isıtılan karıșım daha sonra reaksiyonun gerçekleşeceği reaktöre gönderilmiştir. Öncelikli olarak farklı reaktör türlerinin ve kullanılan termodinamik modellerin (fluid package) etanol dönüşüm oranına olan etkileri incelenmiştir. Sicaklığın ve basıncın dönüşüm oranına ve hidrojen üretim oranına olan etkilerini incelemek için sicaklık $25-500{ }^{\circ} \mathrm{C}$ ve basınç ise 0,01-10 atm arasında değiştirilmiştir.

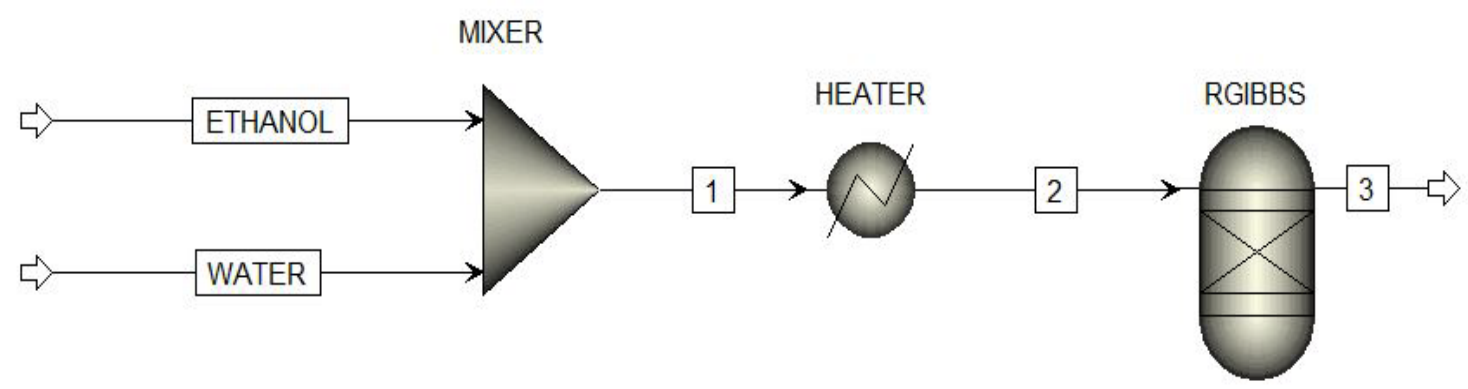

Şekil 1. Steam reforming prosesiyle etanolden hidrojen üretim prosesi

\section{SONUÇ TARTIŞMA}

\subsection{Reaktör Türünün Belirlenmesi}

Farklı reaktör türlerinin etanol dönüşüm oranına ve hidrojen üretim oranına etkilerini incelemek için Aspen Plus simülatöründe yer alan RGibbs, REquilibrium ve RPlug reaktörleri sirasıyla simüle edilmiştir ve reaktörler aynı şartlar altında karşı1laştırılmıștır. Kullanılan üç reaktöre ait Aspen Plus görüntüleri Şekil 2'de verilmiştir.

$\begin{array}{lrr}\begin{array}{l}\text { Reaktörlerin çalışma } \\ \text { değerlendirildiğinde, }\end{array} \text { RGibbs } & \text { reaktörü } \\ \text { termodinamik denge } & \text { halinde } & \text { ürün } \\ \text { konsantrasyonunu belirlemek için Gibbs } & \text { serbest } \\ \text { enerjisini en aza indirirken, REquilibrium reaktörü } \\ \text { reaksiyona ait stokiyometriyi ve reaksiyonlar } \\ \text { arasındaki kimyasal dengeyi kullanarak ürünlere }\end{array}$


ait konsantrasyonu ve aralarındaki faz dengesini belirler. Öte yandan, RPlug reaktörü, reaktör boyu ve yarıçapına bağlı olarak gerçekleșecek reaksiyona ait kinetik parametreleri değerlendirerek oluşacak olan ürünleri konsantrasyonlarına dair detaylı bilgi verir.

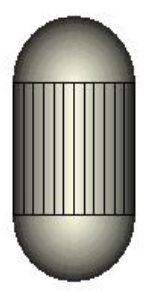

REQUIL

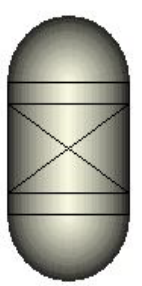

RGIBBS

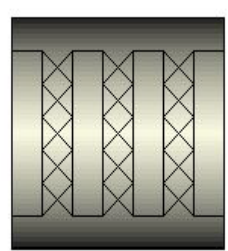

RPLUG
Şekil 2: Analiz edilen reaktör türleri

Reaktör türlerinin başarılı bir şekilde karşılaştırılabilmesi için bu aşamada sıcaklık $500{ }^{\circ} \mathrm{C}$ ve basınç ise $1 \mathrm{~atm}$ olarak belirlenmiştir. Etanol ve su arasındaki steam reforming prosesine ait reaksiyonun stokiyometrisi (etanol/su) $1 / 3^{\prime}$ tür. $\mathrm{Bu}$ nedenle su ve etanol akış hızları sırasıyla 30 ve $10 \mathrm{kmol} / \mathrm{s}$ olarak belirlenmiştir. Burada RPlug reaktörü için yükseklik $1 \mathrm{~m}$ ve yarıçap $0,1 \mathrm{~m}$ olarak alınmıştır. Ayrıca RPlug reaktörünün simüle edilebilmesi için gerçekleşecek reaksiyonun kinetik parametreleri şu şekilde alınmıştır: $\mathrm{k}=0,088, \mathrm{E}=18,4 \frac{\mathrm{kJ}}{\mathrm{mol}}$ ve $\mathrm{T}_{0}=300^{\circ} \mathrm{C}[10]$.

Termodinamik model olarak ise burada UNIQUAC kullanılmıştır. Reaktör performansları Șekil 3 A-B'de verilen etanol dönüşüm oranları ve hidrojen üretimi molar akış hızları dikkate alınarak değerlendirilmiştir. Farklı reaktörlerin etanol dönüşüm oranlarınına olan etkisini gösteren Şekil 3 A'dan da görüleceği gibi belirlenen sıcaklıkta RGibbs ve REquilibrium reaktörlerinde etanol döüşümü \%100 iken RPlug reaktöründe bu oran \%60 civarındadır. Bu sonuç Şekil 3 B'de gösterilen hidrojen molar akış hızı incelendiğindede açıkça görülmektedir. Burada RGibbs ve REquilibrium reaktörlerinin $400{ }^{\circ} \mathrm{C}$ civarında maksimum hidrojen molar akış hızına eriştiği gözlemlenirken, bu oran RPlug için $700{ }^{\circ} \mathrm{C}$ civarındadır. Bununla beraber düşük sıcaklıklarda ise RGibbs reaktörünün REquilbrium reaktörüne oranla daha yüksek hidrojen molar akış hızına sahip olduğu gözlenmektedir. Bu nedenle bundan sonraki aşamalarda en elverişli rektör olması nedeniyle RGibbs reaktörü kullanılmıştır.
A)

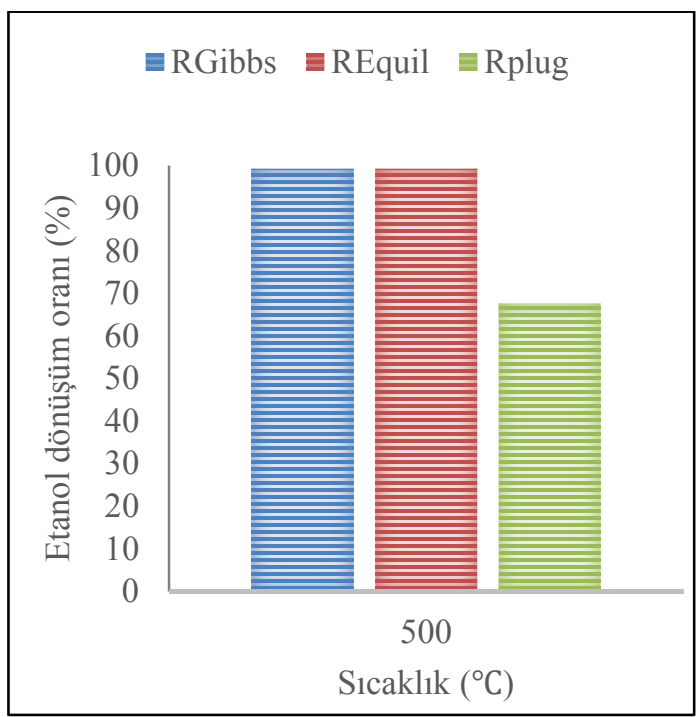

B)

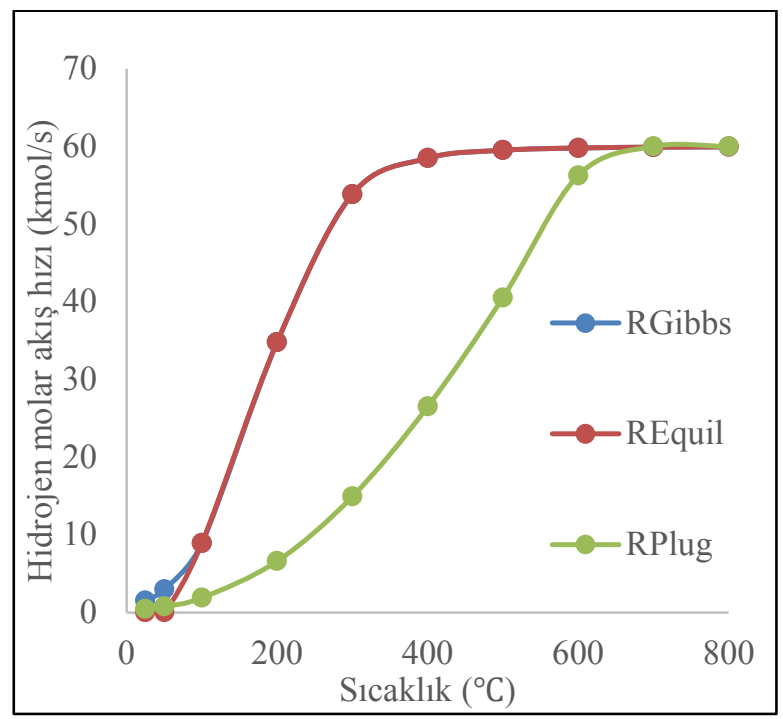

Şekil 3. Reaktör türlerinin etanol dönüşüm oranlarına ve hidrojen molar akış hızına etkisi 
Şekil 3 B ayrıca reaktör sıcaklığının hidrojen molar akış hızına dolayısıyla etanol dönüşüm oranına olan etkilerini de açıkça göstermektedir. Şekilden de görüleceği gibi sıcaklık arttıkça etanol döüşüm oranına bağlı olarak hidrojen akış hızı hizla artmakta ve $400{ }^{\circ} \mathrm{C}$ civarında maksimum değere ulaşmaktadır. Başlangıç sıcaklığı olan $25^{\circ} \mathrm{C}$ hidrojen molar akış hızı $1,51 \mathrm{kmol} / \mathrm{s}$ iken $400{ }^{\circ} \mathrm{C}$ bu değer 59,50 kmol/s olmaktadır. Aynı şekilde etanol dönüşüm oranı incelendiğinde ise dönüşüm oranı $25{ }^{\circ} \mathrm{C} \% 2,5$ iken $400{ }^{\circ} \mathrm{C}$ bu oran $\% 99,18$ olmaktadır.

\subsection{Termodinamik (Fluid Package) Modelin Belirlenmesi}

Farklı termodinamik modeller bünyesinde barındırdıkları farklı reaksiyonlar nedeniyle çok farklı ürün ve yan ürün oluşumları meydana getirmektedirler. Örneğin, metan, etilen, asetaldehit ve aseton gibi yan ürünlerin oluşumuna katkıda bulunan dehidrasyon, dehidrojenasyon ve piroliz gibi reaksiyonlar. Dolayısıyla ürün oluşumlarının tamamen proseste seçilen termodinamik modele bağlı olduğu düşünüldüğünde, proseste kullanılacak olan termodinamik modellerin başarılı bir şekilde karşılaştırılması zorunlu hale gelmektedir.

Etanolden steam reforming prosesiyle hidrojen eldesi prosesinde durum modelleri ve aktivite katsayıs1 modelleri (activity coefficient ve equations of state) siklikla tercih edilmektedirler. Peng-Robinson ve Soave-Redlich-Kwong modelleri en yaygın kullanılan durum (quation of state) modelleridir ve hidrokarbonlar ve hafif gaz karışımları için geliştirilmişlerdir. Öte yandan UNIFAC ve UNIQUAC aktivite katsayısı modelleri (activity coefficient) düşük basınçlarda ideal olmayan sistemlerde siklıkla tercih edilmektedirler. Öte yandan seçilen modeller prosesin veriminide yan ürün oluşumuna bağlı olarak oldukça etkilemektedirler. $\mathrm{Bu}$ çalışma kapsamında Şekil 4'te de verildiği gibi iki farklı aktivite katsayısı modeli karşılaştırılmış olup en iyi dönüşüm oranını veren model belirlenmiştir. Burada sıcaklık $500{ }^{\circ} \mathrm{C}$ ve basınç ise 1 atm olarak alınmıştır. Su ve etanol akış hızları sırasıyla 30 ve $10 \mathrm{kmol} / \mathrm{s}$ olarak alınmış olup reaktör olarak RGibbs kullanılmıştır.

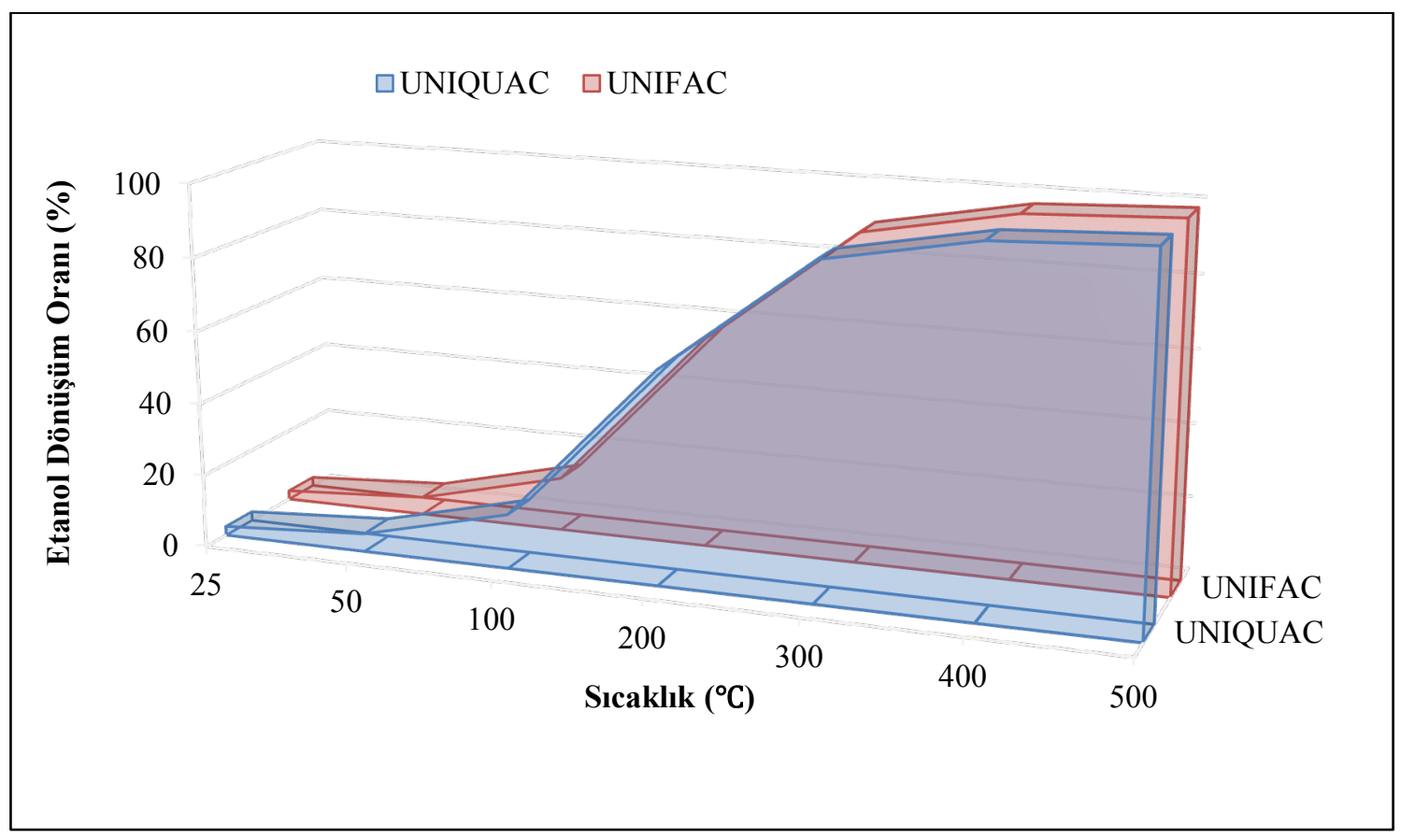

Şekil 4. Aktivite katsayısı modellerinin etanol dönüşüm oranına etkisi 
Şekil 4'ten de açıkça görüldüğü gibi seçilen her iki aktivite katsayısı modeli çalışılan sicaklık aralığında neredeyse aynı dönüşüm yüzdesine sahiptir. Burada UNIQUAC modelinin UNIFAC modeline oranla çalışılan sıcaklık aralığında yaklaşık $\% 0,15^{\prime}$ lik bir farkla daha iyi dönüşüm oranına sahip olduğu belirlenmiştir. Sonuçların birbirine çok yakın olmasının en önemli nedenlerinden bir tanesi de her iki modelinde $\mathrm{H}_{2}$, $\mathrm{CO}_{2}, \mathrm{CO}, \mathrm{H}_{2} \mathrm{O}$ ürün ve yan ürünlerine sahip olmasındandır. Sonuç olarak daha iyi dönüşüm oranına sahip olduğu için bundan sonra çalışmaya UNIQUAC modeli devam edilmiştir.

\subsection{Reaktör Basıncının Etkisi}

Reaktör basıncının etanol dönüşüm oranına olan etkisi Şekil 5'te verilmiştir. Burada yine yukarıda belirtildiği gibi sıcaklık $500{ }^{\circ} \mathrm{C}$ ve basınç ise $1 \mathrm{~atm}$ olarak alınmıştır. Ayrıca su ve etanol akış hızları sırasıyla 30 ve $10 \mathrm{kmol} / \mathrm{s}$ olarak alınmıştır. Reaktör olarak RGibbs ve aktivite katsayısı modeli olarak UNIQUAC kullanılmıştır. Şekil 5'ten de görülebileceği gibi basınç etkisi 0,01 atm ile 10 atm arasında çalışılmıştır. Yüksek basınçlarda dönüşüm oranının düşük olduğu ve yüksek basıncın reaksiyonu negatif etkilediği Şekil 5'te açıkça görülmektedir. Artan basınçla beraber dönüşüm oranın azaldığı tespit edilmiştir. Bunun en önemli nedenlerinden bir tanesi bu reaksiyonun buhar (steam) modunda gerçekleşmesidir. Dolayısıyla basınç arttıkça buhar fazındaki reaktant konsantrasyonu azalmakta ve ürün oluşum hızı azalmaktadır. Öte yandan basıncın azalmasıyla beraber dönüşüm oranının arttığ görülmektedir. Her ne kadar çok düşük basınçlarda dönüşüm oranı daha yüksek olsada, vakum ortamını sağlamak ekstra bir maliyet getireceğinden dolayı bu çalışma kalan aşamalarında \%99 civarında dönüşüm oranı elde edilen atmosferik basınç kullanılmıştır.

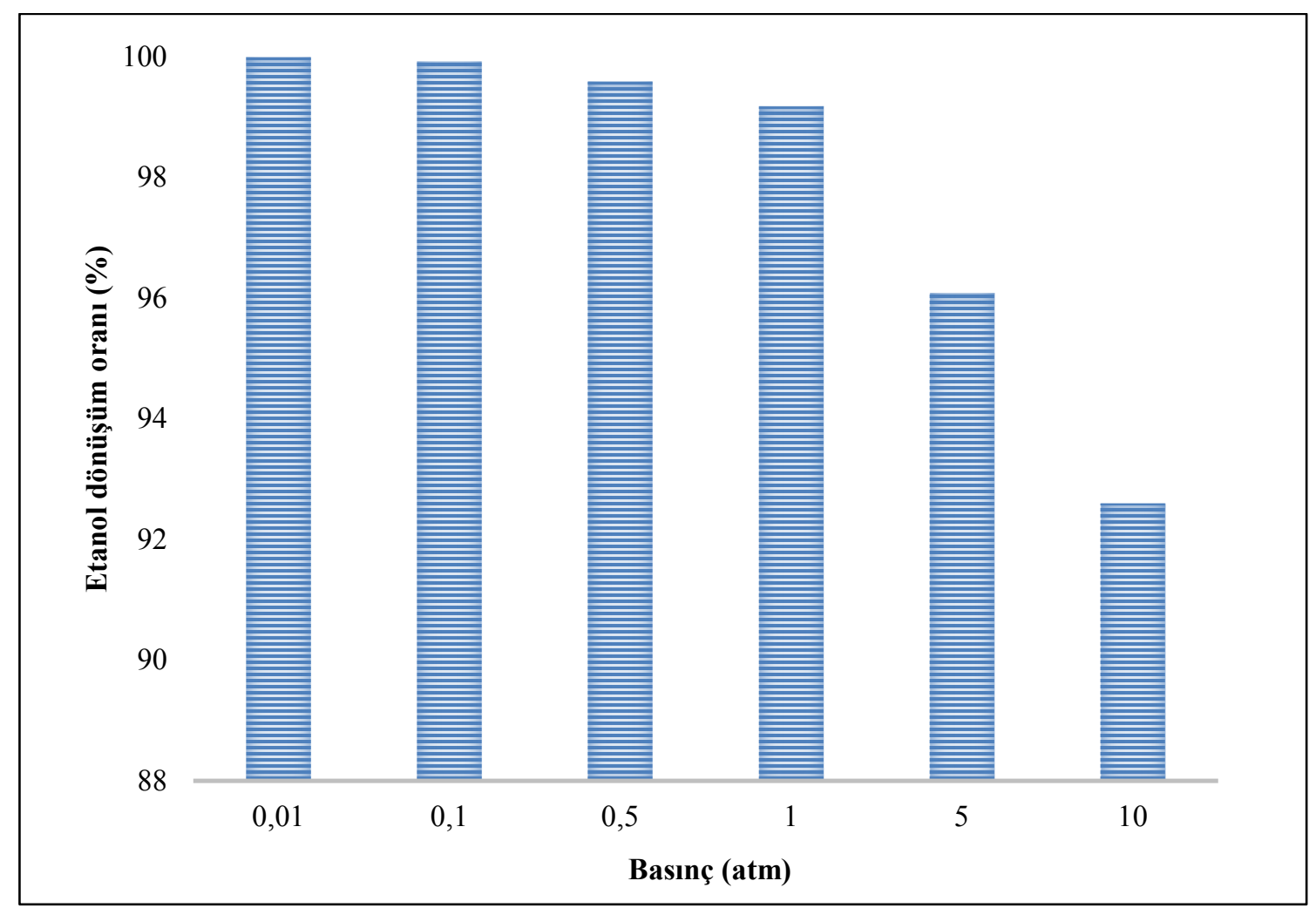

Şekil 5: Reaktör basıncının etanol dönüşüm oranına etkisi 


\subsection{Etanol/Su Karışım Oranının Dönüşüm Oranına Etkisi}

Kimyasal reaksiyonlarda reaktantlar arasındaki karışım oranı, reaksiyon verimliliğini önemli derecede etkilemektedir. Bu çalışma da incelenen etanolün steam reforming prosesinde de bu etkiyi gözlemleyebilmek ve verimi arttırmak için en iyi karışım oranı belirlemek adına farklı karışım oranları incelenmiştir. Farklı etanol/su karışım oranlarının dönüşüm oranına etkisi Şekil 6'da verilmiştir. Şekilden de görüleceği gibi düşük etanol/su karışım oranlarında $(1 / 1$ ve $1 / 2)$ etanol dönüşüm oranı oldukça düşüktür. Bunun en önemli nedeni de etanolün reaksiyona girmesi için ortam yeterli su bulunmamasıdır. Öte yandan $1 / 3$ etanol su karışım oranında her iki reaktant yeterli konsantrasyona sahiptir ve verim \%99,17'dir. Bununla beraber su oranını arttırmak $1 / 3$ 'ten $1 / 4$ 'e arttırmak dönüşüm oranını daha da arttırmış ve $\% 100$ değerine ulaşılmıştır. $\mathrm{Bu}$ noktadan sonra ortama ekstradan su eklemek reaksiyon verimliliği zaten \%100 değerine ulaştığ 1 için etkilememiştir. Dolayısıyla en verimli etanol/su karışım oranı bu çalışmada 1/4 olarak belirlenmiştir.

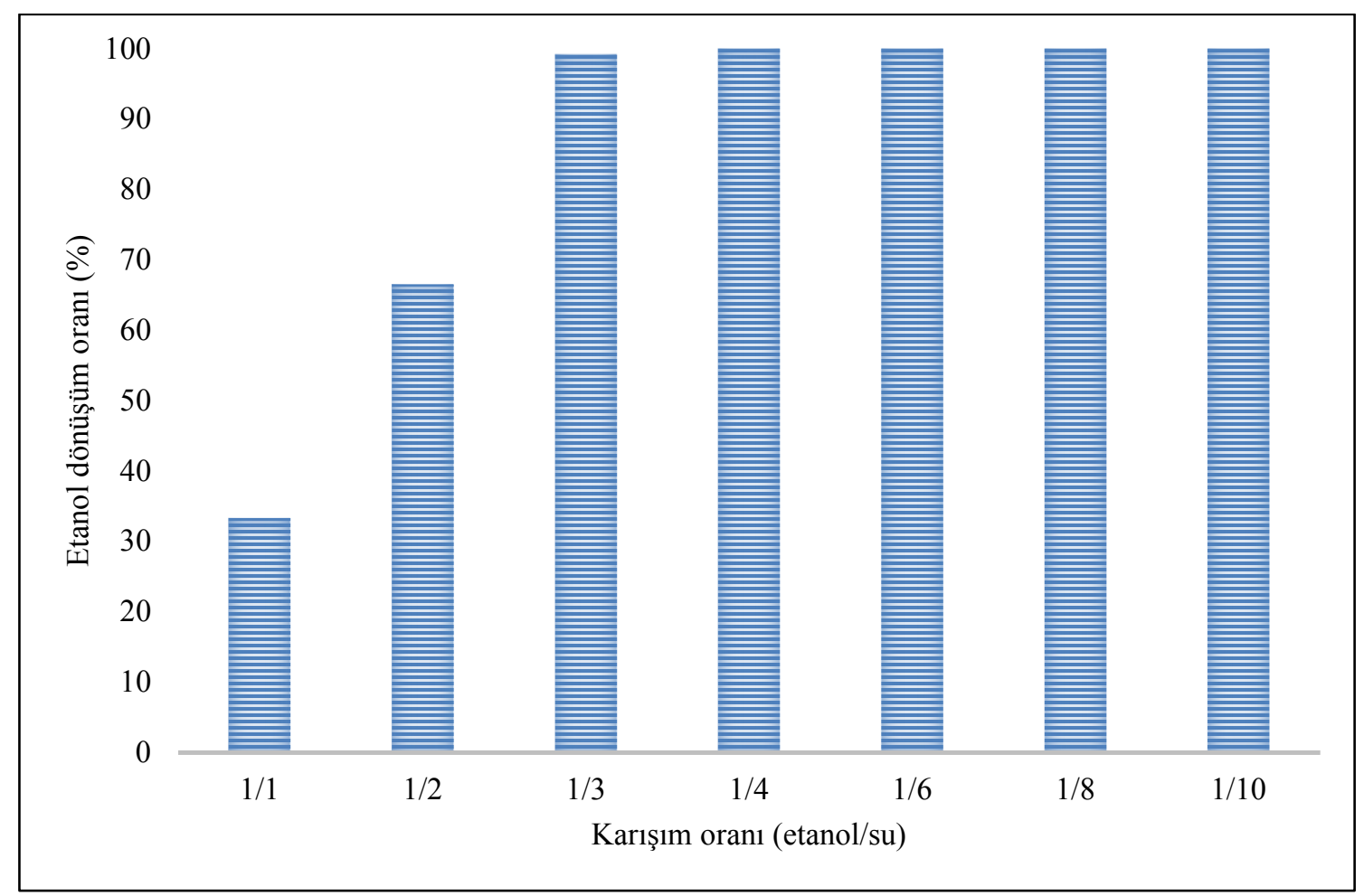

Şekil 6: Etanol/su karışım oranının dönüşüm oranına etkisi

\section{5. Üretilen Hidrojenin Saflaştırılması}

Etanolün su ile reaksiyonundan gerçekleşen steam reforming proesinde ana ürün olan hidrojenin saflaştırılması ve kullanılabilir hale getirilebilmesi için yan ürün olan karbondioksitten ayrıştırılması gerekmektedir. $\mathrm{Bu}$ nedenle bir ayrıştırıcının eklendiği Şekil 7'de verilen simülasyon geliştirilmiştir. Burada RGibbs reaktöründen çıkan ve $\mathrm{H}_{2}$ ve $\mathrm{CO}_{2}$ karışımını içeren üç numaralı stream ayrıştırıcıya (separator) gönderilmiştir. Burada separatöre $\mathrm{H}_{2}$ ve $\mathrm{CO}_{2}$ ayrıştırılması için 1/1 ayrıştırma komutu girilmiştir. Sonuç olarak \%99.9 saflığa sahip $\mathrm{H}_{2}$ ve $\mathrm{CO}_{2}$ iki ayrı stream olarak edilmiştir. 


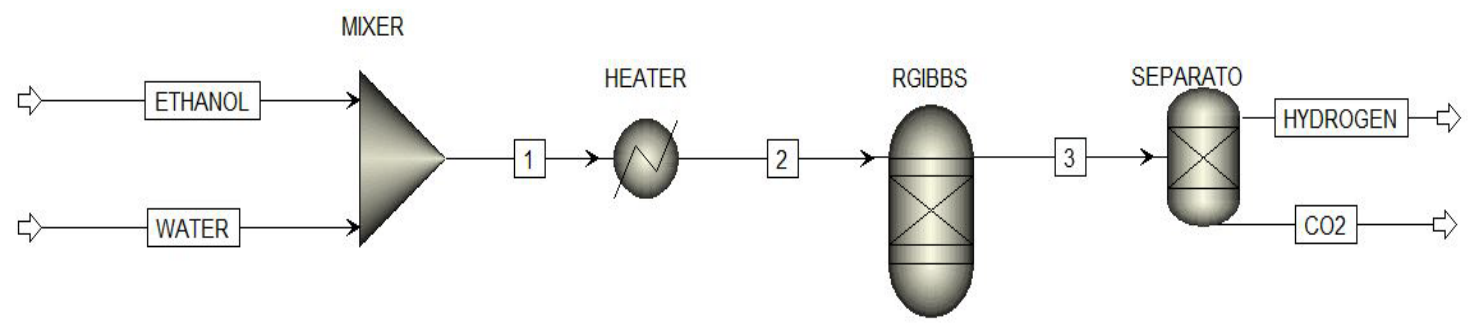

Şekil 7. Üretilen hidrojenin saflaştırılması

\section{SONUÇ}

Doğada bileşikleri halinde bulunan en yaygın element olan hidrojenden elde edilecek olan hidrojen enerjisinin yakın gelecekte içten yanmalı motorlarda yakıt olarak ve yakıt hücreleri yardımıyla elektrik enerjisi üretiminde çok önemli bir yere sahip olması beklenmektedir. Günümüzde hidrojen enerjisi üretmek için kullanılan en yaygın yöntemlerden bir tanesi steam reforming prosesidir. Bu çalışmada Aspen Plus simülatörü kullanılarak reaktör türlerinin ve çalışma parametrelerinin hidrojen etanol dönüşüm oranına ve hidrojen molar akış hızına olan etkisi incelenmiştir. Reaktör türleri olarak RGibbs, REquilibrium ve RPlug reaktörlerinin dönüşüm oranına olan etkileri incelenmiştir ve en verimli reaktör olarak RGibbs belirlenmiştir. Ayrıca UNIFAC ve UNIQUAC termodinamik modellerinin dönüşüm oranına olan etkileri incelenmiş olup en verimli model olarak UNIQUAC belirlenmiştir. Çalışma parametreleri olarak sıcaklık, basınç ve karışım oranları çalışılmış olup en iyi değerler sırasıyla $500{ }^{\circ} \mathrm{C}, 1$ atm ve etanol/su oranı $1 / 4$ olarak tespit edilmiştir. Son olarak üretilen hidrojenin saflaştırılması içi bir ayrıştırıcı (separator) kullanılarak gerçekleştirilmiş olup \%99.9 saflıkta saf H2 elde edilmiştir. Sonuç olarak etanolden steam reforming prosesiyle $\mathrm{H} 2$ üretimi Aspen Plus ile başarılı bir şekilde analiz edilmiştir. Aspen Plus simülatöründen etanolden steam reforming prosesiyle $\mathrm{H}_{2}$ üretimi için elde edilen optimal değerler deneysel $\mathrm{H}_{2}$ üretimi için büyük bir potansiyel olduğunu göstermiştir. Geliştirilen simülasyon ayrıca deney maliyetini vezaman kaybını minimize etmektedir. Dolayısıyla başarılı bir şekilde geliştirilen bu tür simülasyonlar proseslerin tasarımı, kontrolü ve optimizasyonu hakkında olukça faydalı bilgiler sağlamaktadır.

\section{KAYNAKLAR}

1. Kaya, M., Bekiroğullari, M., Saka, C., 2019. Highly Efficient CoB Catalyst Using a Support Material Based on Spirulina Microalgal Strain Treated with $\mathrm{ZnCl} 2$ for Hydrogen Generation Via Sodium Borohydride Methanolysis. International Journal of Energy Research.

2. Navarro, R.M., Pena, M.A. and Fierro, J.L.G., 2007. Hydrogen Production Reactions from Carbon Feedstocks: Fossil Fuels and Biomass. Chemical Reviews, 107, 3952-3991.

3. Wu, Y.J., Santos, J.C., Li, P., Yu, J.G., Cunha, A.F., Rodrigues, A.E., 2014. Simplified Kinetic Model for Steam Reforming of Ethanol on a Ni/Al2O3 Catalyst. The Canadian Journal of Chemical Engineering, 92, 116-130.

4. Hosseini, S.E., Wahid, M.A., 2016. Hydrogen Production from Renewable and Sustainable Energy Resources: Promising Green Energy Carrier for Clean Development. Renewable and Sustainable Energy Reviews, 57, 850-866.

5. Dincer, I., Acar, C., 2015. Review and Evaluation of Hydrogen Production Methods for Better Sustainability. International Journal of Hydrogen Energy. 40, 11094-11111.

6. Soyal-Baltacioğlu, F., Aksoylu, A.E., Önsan, Z.I., 2008. Steam Reforming of Ethanol Over Pt-Ni Catalysts. Catalysis Today, 138,183-186.

7. Özkan, G., Özkan, G., Şahbudak, B., 2016. The Effect of Water/ethanol Mol Ratio to $\mathrm{H}_{2}$ Yield and Selectivity for Hydrogen Production from Reforming of Ethanol with the Pd-NiO, Ni-Cu$\mathrm{Pd} /$ activated Carbon Catalysts, Gazi 
Üniversitesi Mühendislik-Mimarlık Fakültesi Dergisi, 31s.

8. Özkan, G., Şahbudak, B., Özkan, G., 2019. Effect of Molar Ratio of Water/Ethanol on Hydrogen Selectivity in Catalytic Production of Hydrogen Using Steam Reforming of Ethanol, International Journal of Hydrogen Energy, 44, 9823-9829.

9. Murmura, M.A., Patrascu, M., Annesini, M.C., Palma, V., Ruocco, C., Sheintuch, M., 2015. Directing Selectivity of Ethanol Steam Reforming in Membrane Reactors. International Journal of Hydrogen Energy, 40, 5837-5848.

10. Ciambelli, P., Palma, V., Ruggiero, A., 2010. Low Temperature Catalytic Steam Reforming of Ethanol. 2. Preliminary Kinetic Investigation of $\mathrm{Pt} / \mathrm{CeO}_{2}$ Catalysts. Applied Catalysis B: Environmental, 96, 190-197. 
